\title{
STRATEGI MEDIA KEPALA SEKOLAH DALAM MENINGKATKAN KINERJA GURU SDN KALIANGET TIMUR 1 KALIANGET SUMENEP
}

\author{
Suhartinah \\ ${ }^{1}$ SDN Kalianget Timur I Sumenep \\ Email: suhartinah14@admin.sd.belajar.id
}

\begin{abstract}
Abstrak
Upaya kepala sekolah meningkatkan kinerja Guru dengan menggunakan strategi studi banding terhadap sekolah unggulan lainnya, dapat dipahami sebagai tindakan stimulan kepala sekolah tehadap kinerja guru dengan saling berbagi informasi antara satu sekolah dengan sekolah lainnya. Dalam penelitian ini, peneliti akan menjawab beberapa rumusan masalah yang berkaitan dengan tindakan kepala sekolah dalam meningkatkan kinerja guru dengan menggunakan strategi media studi banding. Pertama, bagaimana upaya kepala sekolah dalam meningkatkan kinerja guru sebelum dilakukan studi banding? Kedua, bagaimana kinerja guru setelah diadakan studi banding oleh kepala sekolah?

Metode Penelitian ini, akan menggunakan penelitian tindakan sekolah (PTS) yaitu dengan melakukan tindakan perencanaan, pelaksanaan, pengamatan dan refleksi. Berdasarkan hasil penelitian ini dapat diambil kesimpulan bahwa kinerja guru sebelum dilaksanakan tindakan dapat dibilang stagnan, setelah studi banding dilaksanakan dapat menjadi strategi media peningkatan kinerja guru oleh kepala sekolah. Studi banding sebagai media sharing informasi dan pengalaman guru dalam meningkatkan kinerja. Dan kinerja guru semakin menunjukan performance yang lebih baik.
\end{abstract}

Kata kunci: studi banding, kepala sekolah, kinerja Guru

\begin{abstract}
The principal's efforts to improve teacher performance by using comparative study strategies against other excellent schools. It can be understood as a stimulant action of the principal to the performance of teachers by sharing information between one school and another school. In this study, researchers will answer several formulations of problems related to the actions of principals in improving teacher performance by using comparative study media strategies. First, how is the principal's efforts in improving teacher performance before the comparative study? Second, how does the teacher perform after the comparative study by the principal?

This research method, will use school action research (PTS) that is by carrying out actions of planning, implementation, observation and reflection. Based on the results of this study can be concluded that the performance of teachers before the implementation of actions can be said to be stagnant, after the comparative study is implemented can be a media strategy to improve teacher performance by the principal. Comparative studies as a medium of sharing information and teacher experience in improving performance. And the performance of teachers increasingly shows improved performance.
\end{abstract}

Keywords: comparative studies, principal, Teacher performance

\section{PENDAHULUAN}

Kemajuan pembangunan dalam berbagai aspek kehidupan berdampak signifikan terhadap perkembangan pendidikan. Perkembangan yang berpengaruh dalam bidang pendidikan antara lain terkait pola interaksi dan perilaku antara guru dan siswa, siswa satu dengan lainnya baik dalam lingkungan sekolah maupun pergaulan bermasyarakat, metode pembelajaran dan gaya belajar siswa harus dikembangkan dengan melakukan 
inovasi dan kreasi untuk meningkatkan hasil belajar dan pembelajaran yang lebih baik (Wim Hoopers, 2004:vii).

Pekembangan dan tantangan pembelajaran menunjukkan pembaharuan dalam berbagai aspek. Karena situasi dan kondisi yang demikian, perlu kiranya para guru diberikan pengenalan serta diajak sharing membuka cakrawala pengetahuan dengan mencoba pengalaman berbeda, yaitu dengan melakukan studi banding ke sekolah unggulan yang memiliki reputasi yang baik, latar belakang, dan situasi-kondisi yang berbeda dari perkembangan pendidikan SDN Kalianget 1.

Adalah SDN Kalianget Timur I satu Sekolah Dasar (SD) Negeri yang berlokasi di Jl. Raya Kalianget No. 2 Kalianget Timur Kalianget Sumenep, dan saat ini sudah terakreditasi A dengan nomor NPSN 20551818. Kepala sekolah berkeinginan memajukan SDN Kalianget dengan melakukan langkah-langkah pengembangan bersama seluruh warga sekolah khususnya guru dan karyawan.

Pengembangan sekolah dasar yang diinginkan dan dilakukan kepala sekolah mempunyai fokus pada pengembangan akademik dan non akademik. Hingga kini, jumlah siswa lebih dari 200 siswa, dengan 11 ruang kelas, sedangkan pengembangan non akademik berporos pada unsur budaya, agama dan olahraga. Pengembangan dalam bidang akademik pada proses pelajaran di sekolah menyesuaikan dengan kurikulum yang dikembangkan di SDN Kalianget 1 dan perbaikan saranaprasarana yang menjadi penunjang lainnya. Untuk meningkatkan pengembangan bidang akademik SDN Kalianget 1, kepala sekolah mengambil berbagai langkah, salah satunya dengan mengadakan Studi Banding ke MI Nahdlatul Ulama Tarate Gresik sebagai media strategi dengan tujuan meningkatkan kinerja para guru. Studi banding sebagai upaya meningkatkan kinerja guru dengan melakukan sharing pengalaman dan melaksanakannya tanggung jawab sebagai pendidik dengan efektif dan efesien. Oleh karenanya, kepala sekolah dapat memberdayakan dengan mengembangkan potensi para guru dalam kegiatan akademik secara maksimal. Hal ini merupakan kunci peran dan tanggung jawab kepala sekolah dalam pendidikan adalah dengan memberdayakan dan mengembangkan potensi para guru dengan memberi mereka kesempatan secara maksimal guna mengembangkan belajar siswanya (Marhan, 2017: 74). Karena para guru memiliki titik tolak sentral dalam peningkatan kualitas proses pebelajaran (Etisnawati, 2020: 13).

MI Nahdlatul Ulama Tarate Gresik adalah salah satunya Sekolah unggulan yang terletak di Jl. KH. Abdul Karim No.60, Trate, Pekelingan, Kec. Gresik, Kabupaten Gresik, Jawa Timur 61114. Akreditasi MINU Trate putera Gresik adalah A, dengan No. SK. Akreditasi 200/BAP-S/M/SK/X/2016. Lembaga Satuan pendidikan ini di bawah di lingkungan Yayasan Perguruan Pendidikan NU Trate Putri Gresik.

MINU Trate putra Gersik menjadi buah bibir guru dan masyarakat karena termasuk salah satu sekolah prestasi di Jawa Timur. Tentu hal ini, menjadi motivasi tersendiri bagi SDN Kalianget 1 untuk mengetahui kondisi objektif yang dimaksud antara lain lokasi sekolah, pengembangan 
pembelajaran, kegiatan kesiswaan, maupun sistem administrasi sekolah.

Untuk itu rumusan masalah dalam penelitian ini akan menjawab pertanyaan sebagai berikut : Pertama, bagaimana upaya kepala sekolah dalam meningkatkan kinerja guru sebelum dilakukan studi banding? Kedua, bagaimana kinerja guru setelah diadakan studi banding oleh kepala sekolah?

\section{METODE PENELITIAN}

Metode penelitian ini menggunakan penelitian tindakan sekolah (PTS) dengan empat (4) tahapan dengan menggunakan dengan pendekatan kualitatif (Husaini Usman, 2011: 152154) yaitu 1. Perencanaan, adalah langkah awal sebelum peneliti melakukan tindakan, yaitu merencanakan program kegiatan studi banding untuk meningkatkan kinerja guru dengan menelaah problem kinerja guru, memetakan dan memberi pandangan. Kemudian mendesain konsep studi banding, dan membuat proposal studi banding sebagai acuan dalam pelaksanaan studi banding lengkap SOP yang akan dilaksanakan, 2. Pelaksanaan, pada tahapan ini peneliti melaksnakan studi banding bersama para guru sebagai strategi media meningkat kinerja guru ke MINU Terate Gresik, pada pelaksanaan studi banding ini mengikuti perencanaan dan SOP yang sudah disiapkan sebelumnya agar terjadi kesesuaian antara yang direncanakan dengan pelaksanaan di lapangan pada saat studi banding. dan 3. Pengamatan, yaitu mengamati pada saat pelaksanaan tindakan dan sesudah pelaksanaan dengan menggunakan format penilaian dengan menggunakan indikator-indikator dalam proses peningkatan kinerja Guru dengan meminta pengawas untuk memberi penilaian secara objektif dan serta menggunakan video perekam sebagai bahan evalusi jika ada hal-hal yang terlewati. 4. Refleksi sebagai upaya peneliti merenungkan hasil pengamatan penelitian, apakah antara perencanaan hingga proses pelaksanaan, serta mengikutsertakan para guru yang menjadi objek saat pelaksanaan berlangsung termasuk kesan-kesan hasil dari studi banding dan pesan terhadap pelaksnaaan siklus selanjutnya.

\section{HASIL DAN PEMBAHASAN}

\section{Pengertian Studi Banding dan Tujuannya}

Studi banding merupakan sebuah konsep belajar yang dilaksanakan pada tempat lokasi dan situasi serta kondisi berbeda dengan maksud menambah wawasan dan pengetahuan baik dalam rangka peningkatan mutu, perluasan usaha, perbaikan sistem, penentuan kebijakan baru, perbaikan peraturan perundangan, dan lain-lan (Mahiska, 2013).

Kegiatan studi banding dapat dilaksanakan oleh kelompok kepentingan dalam rangka mengunjungi atau observasi, melakukan diskusi tentang tema tertentu dengan perencanaan dan waktu pelaksanaan singkat. Proses pelaksanaan studi banding adalah dalam rangka membandingkan antara kondisi obyek yang menjadi tujuan studi banding dengan situasi dan kondisi yang terjadi tempat asal pengunjung. Harapan dari studi banding adalah mendapatkan informasi secara detail dalam melakukan 
pengumpulan data dan informasiinformasi perbandingan sebagai bahan diskusi kembali dalam merumuskan konsep yang menjadi tujuan.

Untuk memaksimalkan hasil studi banding perlu kiranya, peserta membuat persiapan yaitu merumuskan hal urgen yang akan dilakukan peninjauan saat studi dan mengevaluasi kondisi objektif internal lembaga, tentang apa saja yang akan dilakukan untuk pengembangan dan upgrating program yang sudah ada.

Tujuan utama dari kegiatan studi banding adalah melakukan penggali data dan informasi secara teknis real dan empiris yang terjadi di lapangan. Data dan informasi tersebut diolah kemudian menjadi acuan untuk program pengembangan internal. Dengan demikian tujuan dari studi banding yaitu :

1. Untuk menambah wawasan internal lembaga

2. Perkaya pengalaman baru

3. Melakukan perbandingan internal dan eksternal

4. Membuka cakrawala berfikir

\section{Strategi Media Kepala Sekolah}

Media Strategi adalah suatu kegiatan untuk memilih sarana yang ingin digunakan sebagai sarana komunikasi dari komunikan ke khalayak dengan tujuan dan maksud tertentu. Perencanaan strategi media meliputi penentuan sarana khusus yang dipilih dan mengalokasikan anggaran tentang pelaksanaan media yang akan digunakan serta penyusunan jadwal strategi media yang akan dilaksanakan (Imron Arifin, 2004 : 41).

Strategi adalah pendekatan secara keseluruhan yang berkaitan dengan pelaksanaan gagasan, perencanaan, dan aktivitas dalam kurun waktu tertentu. Di dalam strategi yang baik terdapat koordinasi tim kerja, memiliki tema, mengidentifikasi faktor pendukung yang sesuai dengan prinsip-prinsip pelaksanaan gagasan secara rasional, efisien dalam pendanaan, dan memiliki taktik untuk mencapai tujuan secara efektif (Sri Banun, 2016 :139).

Oleh karenanya, kepemimpinan sekolah dapat terlihat dalam diri kepala sekolah yang tumbuh kesadaran dan pemahaman yang mendalam terhadap makna kepemimpinan dalam menjalankan, memilih strategi beserta aspek-aspeknya lainnya seperti keterampilan kepemimpinan, dimensi kepemimpinan, dan fungsi-fungsi kepemimpinan, sehingga pemimpin mampu mengembangkan kaderisasi kepemimpinan secara produktif dan berkualitas (Marhan, 2017: 75).

Untuk itu, peran kepala sekolah sebagai pemimpin pendidikan dapat menciptakan situasi sekolah yang aman dan nyaman dalam meningkatkan pembelajaran baik untuk guru maupun siswa, sehingga guru-guru dapat mengajar dan murid-murid dapat belajar dengan baik. Dalam melaksanakan peran tersebut, kepala sekolah memiliki tanggungjawab ganda yaitu melaksanakan administrasi sekolah sehingga tercipta situasi belajar mengajar yang baik, dan melaksanakan supervisi sehingga guru-guru lebih bersamangat dalam menjalankan tugastugas pengajaran dan dalam membimbing pertumbuhan murid-murid (Sri Banun, 2016 : 140).

Adapun dalam perspektif kebijakan pendidikan nasional terdapat tujuh peran 
utama kepala sekolah yaitu: (1) educator (pendidik), (2) manajer, (3) administrator, (4) supervisor, (5) leader (pemimpin), (6) pencipta iklim kerja, dan wirausahawan (Zulkifli, 2014 : 309).

\section{Meningkatkan Kinerja Guru}

Kinerja guru berkaitan dengan kompetensi guru, artinya agar memiliki kinerja yang baik seorang guru harus didukung dengan kompetensi yang baik pula. Jika seorang guru tidak memiliki kompetensi yang baik maka tidak akan mungkin memiliki kinerja yang baik. Depdiknas (2004: 11) menyatakan kinerja guru adalah kemampuan guru untuk mendemonstrasikan berbagai kecakapan dan kompetensi yang dimilikinya. Esensi dari kinerja guru tidak lain merupakan kemampuan guru dalam menunjukkan kecakapan atau kompetensi yang dimilikinya dalam dunia kerja yang sebenarnya.

\section{Profil SDN Kalianget Timur 1}

SDN Kalianget Timur I salah satu Sekolah Dasar (SD) Negeri yang berlokasi di Jl. Raya Kalianget No. 2 Kalianget Timur Kalianget Sumenep. Dengan NPSN : 20551818

Jumlah tenaga Guru sebanyak 17 orang, dengan Siswa sejumlah 210 dibagi dalam 11 Ruang Kelas dengan dipimpin kepala sekolah Suhartinah. Sekolah Dasar ini pernah menjadi sekolah percontohan di Kecamatan Kalianget pada tahun 2017.

Penetapan SD rujukan itu sendiri, sebagai upaya pemerintah dalam menyediakan sekolah bermutu, untuk dapat dijadikan acuan penyelenggaraan pendidikan SD. Dan keberadaannya sesuai dengan amanat UU Nomor 20
Tahun 2013 tentang Sistem Pendidikan Nasional," Kata Suhartina, S.Pd. Selaku kepala Sekolah SD Kalianget Timur 1.

Prestasi membanggakan ini tentu bukan titik berhenti untuk melakukan pengembangan sekolah, akan tetapi merupakan pemecut untuk semakin meningkat performance SDN Kalianget 1. Salah satu upaya kepala sekolah untuk meningkatkan performan dengan melakukan studi banding ke MINU Terate Gresik.

\section{Studi Banding Sebagai Media Strategi Kepala Sekolah Meningkat Kinerja Guru}

Pra Siklus

Kondisi kinerja guru SDN Kalianget Timur 1, dari 17 guru bisa dikatakan mendekati kata ideal. Dengan indikator Pertama, kemampuan merencanakan pembelajaran dapat terealisasi dengan baik. Kedua, kemampuan guru mengorganisasi pembelajaran berjalan sesuai rencana. Namun yang menjadi persoalan adalah meningkatkan performan (kinerja) dengan inovasi dan kreatifitas kurang sesuai dengan perkembangan pembelajaran dan pengornisasian yang lebih efektif dan efisien di era sekarang. Sehingga kepala sekolah perlu memberi tindakan mentoring lebih lanjut. Agar kualitas kinerja para guru makin ideal dengan melakukan studi banding pada sekolah yang lebih maju/unggul.

Oleh karenanya, ada langkah dalam peningkatan kinerja guru, yaitu : pertama, dilakukan mentoring dengan mengunjungi lembaga ahli bidang pegembangan pembelajaran sekolah Dasar (SD) kedua, studi banding Ke sekolah unggul di Jawa Timur. 
Siklus 1

1. Perencanaan: Perencanaan program kegiatan studi banding untuk meningkatkan kinerja guru dengan menelaah problem kinerja guru, meningkatkan performan (kinerja) dengan inovasi dan kreatifitas sesuai perkembangan pembelajaran dan pengornisasian lebih efektif dan efisien. memetakan dan memberi pandangan bahwa kunjungan pertama akan dilakukan kepada ahli. Kemudian mendesain Jadwal dan konsep studi banding dengan jadwal sebagai berikut :

Tabel 1: Jadwal Studi banding ke Ahli SDN Kalianget Timur I

\begin{tabular}{|l|l|l|l|}
\hline No & Kegiatan & Tgl/Jam & Penjab \\
\hline 1 & Pembukan & Sabtu & Kepala \\
& pengarahan & $1 \quad$ April & Sekolah \\
& Kepala sekolah & $2021 \mathrm{M}$ & \\
& & $07.30-$ & \\
& & 80.00 & \\
\hline 2 & Mentoring dan & $08.00-$ & Ahli dari \\
& sarasehan ahli & 10.30 & STKIP \\
\hline 3 & Evaluasi dan & $10.30-$ & PGRI \\
& pendampingan & 12.00 & Sumenep \\
\hline
\end{tabular}

2. Tindakan

Pada saat pelaksanaan semua guru di SDN Kalianget 1 berkumpul tepat waktu sesuai jadwal yang sudah disepakati, langkah pertama kepala sekolah memberi pengarahan pada semua hadirin dengan memberi motivasi pentingnya melakukan inovasi dan kreatifitas dalam proses perencanaan pembelajaran dan pengorgisasian pembelajaran sebagai indikator dari kinerja guru. Setelah dilaksanakan pembukaaan ahli dari STKIP PGRI Sumenep memberi materi tentang urgensi perencanaan pembelajaran

dan

pengorganisasian pembelajaran sebagai indikator dari kinerja guru dalam hal ini juga berbagi pengalaman tentang kinerja guru sekolah unggulan di Jawa timur, salah satunya MINU Tarete Gresik yang melaksanakan pembelajaran begitu efektif dan efisien dalam perencanaan dan pengorganisian pembelajaran.

Pelaksanakaan studi banding teori dalam mentoring (sarasehan), kepada para guru diminta untuk mengevaluasi dan pendampingan dengan ditemukan beberapa point penting sebagai bahan perenungan. Diantaranya, terdapat 10 orang guru yang antusias memahami pentingnya meningkatkan kinerja guru dengan melaksanakan tugastugas perencanaan pembelajaran dan pengorganisasian pembelajaran.

Sedangkan 7 orang lainnya kurang maksimal dalam melaksanakan tugas, hal ini terlihat dari hasil pemberian tugas kurang begitu tepat dan masih menggunakan bahan-bahan yang dimiliki sebelumnya.

3. Pengamatan

Dilakukan pengamatan dari rangkaian pelaksanaan studi banding teoritis oleh ahli. Dan ditemukan beberapa kendala oleh 7 orang guru. Peneliti berusaha wawancara dan dokumentasi dengan para guru, peneliti menemukan beberapa jawaban yang membuat kurang maksimal 
dalam pengerjaan tugas saat pelaksanaan teoritis, yaitu :

1. Guru belum merasa memahami secara maksimal dari rangkaian pemaparan tutor/ahli.

2. Guru belum bisa konsentrasi secara penuh karena beban kerja yang terlalu pendek pengerjaannya.

3. Guru merasa kurang maksimal karena tidak konkrit pada pelaksanaan perencanaan pembelajaran dan pengorganisasian pembelajaran.

Dari tiga hal pengamatan dengan menggunakan wawancara dan dokumentasi, perlu refleksi terhadap 7 orang guru tersebut di atas.

4. Refleksi

Berdasarkan pada hasil pengamatan di siklus 1 dengan ditemukan 10 orang telah melaksanakan tugas dengan baik mendekati sempurna dan 7 orang belum maksimal dalam pengerjaan tugas, maka dilakukan tindakan (pelaksanaan) dengan menggunakan studi banding bersama ahli. Peneliti mencoba merefleksikan siklus pertama dengan uraian sebagai berikut : Pertama, perlu dilakukan studi banding dengan sekolah yang unggulan di Jawa Timur. Kedua, persiapan waktu, tenaga dan anggaran studi banding oleh sekolah dan para guru, Ketiga, desain kembali perencanaan studi banding dengan menambah kolom jadwal pengamatan /observasi langsung ke dalam kelas, setelah dilakukan sesi sarasehan bersama para guru dan kepala sekolah di tempat tujuan studi banding. Keempat, pada siklus kedua perlu memperhatikan hasil siklus permata.

Tabel 2: Hasil siklus 1 Kinerja Guru

\begin{tabular}{|c|c|c|}
\hline No & $\begin{array}{c}\text { Hasil } \\
\text { Evaluasi }\end{array}$ & Indikator \\
\hline 1 & 10 Orang & $\begin{array}{l}\text { 1. Mengerjakan Tugas } \\
\text { dengan tepat waktu } \\
\text { 2. Menunjukkan } \\
\text { performan yang } \\
\text { baik ketika } \\
\text { pelaksanaan sesi } \\
\text { pelaksanaan }\end{array}$ \\
\hline 2 & 7 orang & $\begin{array}{l}\text { 1. } \text { Mengerjakan } \\
\text { Tugas dengan } \\
\text { tidak tepat waktu } \\
\text { 1. Menunjukkan } \\
\text { performan yang } \\
\text { kurang baik ketika } \\
\text { pelaksanaan sesi } \\
\text { pelaksanaan }\end{array}$ \\
\hline
\end{tabular}

\section{Siklus 2}

1. Perencanaan

Perencanaan program kegiatan studi banding sebagai upaya meningkatkan kinerja guru dengan menelaah problem kinerja guru, meningkatkan performan (kinerja) dengan inovasi dan kreatifitas sesuai perkembangan pembelajaran dan pengorganisasian lebih efektif dan efisien. Memetakan dan memberi problem yang terjadi saat dilakukan kunjungan pertama akan dilakukan kepada ahli dengan dilakukan desain Jadwal dan konsep studi banding kembali dengan menambahkan pola tindakan jadwal sebagai berikut : 
Tabel 3: Jadwal Studi banding ke MINU terate Gresik

\begin{tabular}{|c|c|c|c|}
\hline No & Kegiatan & Tgl/Jam & Penjab \\
\hline 1 & $\begin{array}{l}\text { Pembukan } \\
\text { pengarahan } \\
\text { Kepala sekolah }\end{array}$ & $\begin{array}{l}\text { Sabtu } \\
10 \quad \text { April } \\
2021 \mathrm{M} \\
11.30- \\
12.00\end{array}$ & $\begin{array}{l}\text { Kepala } \\
\text { Sekolah }\end{array}$ \\
\hline 2 & $\begin{array}{l}\text { Mentoring dan } \\
\text { sharing } \\
\text { bersama }\end{array}$ & \multirow[t]{3}{*}{$\begin{array}{l}12.00- \\
14.30\end{array}$} & \multirow{3}{*}{$\begin{array}{l}\text { Bersama } \\
\text { Kepala } \\
\text { sekolah, } \\
\text { Guru } \\
\text { MINU } \\
\text { Gresik } \\
\text { Terate }\end{array}$} \\
\hline 3 & $\begin{array}{l}\text { Kunjungan } \\
\text { Kelas }\end{array}$ & & \\
\hline 3 & $\begin{array}{l}\text { Evaluasi dan } \\
\text { pendampingan }\end{array}$ & & \\
\hline
\end{tabular}

2. Tindakan

Pelaksanaan Studi banding ke MINU Terate Gresik dilkasanakan tanggal 10 april 2021, pukul 11.00 WIB baru sampai di lokasi, dan dilanjutkan dengan penyambutan oleh pihak sekolah dan mengisi daftar hadir.

Selesai menuju ruang pertemuan dengan sambil berkenalan satu sama lain, acara studi banding dimulai dengan sambutan dari kedua belah pihak antara SDN Kalianget Timur 1 dan MINU Terate Gresik. Lebih lanjut kedua sekolah saling berbagi tips peningkatan kinerja guru oleh kepala sekolah, juga sharing bersama guru MINU terate gresik terkait perencanaan pembelajaran dan pengorganisasian pembelajaran dalam kelas.

Setelah dilakukan sharing bersama (Mentoring), para guru diajak berkunjung ke kelas dengan dipandu siswa dan didampingi guru. Saat kunjungan kelas yang menjadi pemandu adalah siswa. la bercerita tentang pengalamannya dalam pembelajaran di kelas. Sehingga kesan kesan terhadap guru SDN kalianget 1 sangat mendalam, karena proses kunjungan kelas bukan guru yang bercerita tentang proses pembelajaran di kelas melainkan berdasarkan hasil pengalaman siswa secara detail.

Setelah selesai kunjungan kelas, para guru diminta untuk melakukan refleksi pengalaman studi banding, sharing bersama guru dengan menggunakan form yang telah disediakan oleh kepala sekolah terkait studi banding $\mathrm{Ke}$ MINU Terate Gresik.

Hasilnya ditemukan bahwa 17 orang guru SDN Kalianget Timur 1 merasa puas dengan pelaksanaan studi banding, dan merasa waktu yang tersedia kurang lebih lama. Hal ini menunjukkan bahwa studi banding ke MINU terate Gresik menunjukkan Indikator keberhasilan. Selanjutnya pasca studi banding kepala sekolah meminta untuk melanjutkan pengerjaan tugas perencanaan pembelajaran dan pengorganisasian pembelajaran yang dilaksanakan di kelas masing-masing.

Hasilnya pun menunjukkan hasil yang sama dengan hasil refleksi pengalaman pada pengisian form dengan hasil 17 orang menunjukkan performan/ kinerja guru yang makin ideal dengan melakukan inovasi dan kreasi pembelajaran berdasar informasi yang didapat.

3. Pengamatan

Berdasarkan pengamat studi banding ke MINU Terate kepala 
sekolah dan para Guru menunjukkan antusiusme yang tinggi, ini ditunjukkan dari keseriusan para guru melakukan diskusi dan melakukan tanya jawab secara maksimal.

Berdasarkan pengamatan peneliti bahwa melihat semakin bersemangatnya para guru dalam melaksanakan proses studi banding karenakan factor performan dari MINU terate yang melaksanakan proses pendidikan sangat laur biasa dan sangat ramah dalam hal komunikasi dan penyambutan, ditambah dengan berdirinya gedung megah 3 lantai lengkap dengan fasilitas dan antraksi penampilan para siswa menyambut rombongan para guru SDN Kalianget Timur 1. Dengan ini Guru merasa betah mendengar penjelasan dan penyambutan dari MINU terate.

4. Refleksi

Proses studi banding ke MINU terate membawa hasil yang memaksimal terhadap peningkatan kinerja guru berjalan dengan baik. hal ini terlihat dengan indicator: 1. Pelaksanaan perencanaan pembelajaran dapat disempurnakan dengan berdasar pada pengalaman dan hasil sharing dari studi banding. 2 . Performan kinerja guru terlihat dari proses pengorganisasian pembelajaran berjalan dengan efektif dan efisien. 17 orang guru setiap hari melakukan sharing tentang problem dan inovasi apa yang akan dilaksanakan pada masing-masing kelas. Sehingga proses pembelajaran

dari perencanaan

dan

pengorganisasian pembelajaran berjalan efektif dan efisien dengan sentuhan inovasi dan kreasi setiap melakukan pembelajaran.

\section{Analisis}

Berdasarkan hasil siklus 1 dan siklus 2 program studi banding mengalami peningkatan bertahap (step by step) dan dapat dianalisis bahwa terdapat perbedaan tingkat kinerja guru dalam melaksnakan tanggung jawabnya sebagai pendidik. Kinerja guru adalah kemampuan guru untuk mendemonstrasikan berbagai kecakapan dan kompetensi yang dimilikinya dalam pembelajaran baik di dalam kelas maupun di luar kelas. Substansi dari kinerja guru adalah bagaimana guru mampu membuat suasana kelas dan perasaan siswa lebih nyaman belajar bukan memaksa siswa untuk tahu pengetahuan. Apalagi, seorang guru adalah sosok yang di "gugu dan ditiru", karenanya setiap kata dan tindakan merupakan titik belajar siswa di sekolah sehingga kemampuan dan kompetensi guru perlu untuk ditingkatkan agar pembelajaran di sekolah dapat berjalan sesuai harapan. Dalam hal ini dicatat beberapa hal dari indikator perencanaan dan pengorganisasian pembelajaran, sebagai berikut:

Tabel 4: Analisis perbandingan antara siklus 1 dan 2 studi banding

\begin{tabular}{|c|c|c|c|}
\hline No & Siklus 1 & Siklus 2 & Indikator \\
\hline 1 & $\begin{array}{c}10 \\
\text { Orang }\end{array}$ & $\begin{array}{c}17 \\
\text { orang }\end{array}$ & $\begin{array}{lr}\text { Menunjukkan } & \\
\text { performan yang } \\
\text { maksimal dengan } \\
\text { menyelesaikan } \\
\text { tugas } & \\
\begin{array}{ll}\text { Pendamping dutor, } \\
\text { kepala sekolah }\end{array}\end{array}$ \\
\hline 2 & 7 orang & - & $\begin{array}{l}\text { Menunjukkan } \\
\text { performan yar }\end{array}$ \\
\hline
\end{tabular}




\begin{tabular}{|l|l|l|}
\hline & & tidak maksimal \\
& dengan tidak \\
menyelesaikan tutor, \\
tugas dan \\
Pendamping dan \\
kepala sekolah
\end{tabular}

\section{KESIMPULAN}

Berdasarkan hasil penelitian dan pembahasan di atas dapat disimpulkan bahwa studi banding dapat menjadi strategi media kepala sekolah dalam meningkatakn kinerja guru, dengan melakukan sharing pengetahuan guru dan dapat menambah ilmu dan pengetahuan yang luas. $\mathrm{Hal}$ ini berdampak terhadap peningkatan kinerja guru terutama dalam perencanaan dan pengorganisasian pembelajaran sebagai tugas utama sebagai pendidik yang mempunyai kompetensi profesional.

\section{DAFTAR PUSTAKA}

Etisnawati (2020). Strategi kepala sekolah dalam peningkatan mutu tenaga Hopper, Wim (2004). Orientasi Pendidikan Dasar. Ciputat: Logo Wacana IImu.

Mahiska.(2023). Pengertian Study banding dan cara melaksanakan Study banding http://rembangonline.blogspot.com/2013/05/pengertian-dan-caramelaksanakan-study.html

Marhan (2017). Upaya Kepala Sekolah Dalam Mmeningkatkan Kinerja Guru Pendidik. Jurnal EDUCATIO (Jurnal Pendidikan Indonesia): Vol. 6 (1), 13-18.

Pendidikan Agama Islam (PAI) Di SMA Negeri 4 Pagaralam. Jurnal al-Bahtsu: Vol. 29(1), 73-86.

Sri Banun, dkk. (2016).Strategi Kepala Sekolah Dalam Meningkatkan Mutu pendidikan pada SMP Negeri 2 Unggul Mesjid Raya Kabupaten Aceh Besar. Jurnal Administrasi Pendidikan Pascasarjana Universitas Syiah Kuala : Volume 4 (1), 137- 147.

Usman, Husaini, dkk. (2011) Metode Penelitian Sosial. Jakarta :Bumi Aksara

Zulkifli.(2014). Strategi Kepala Sekolah Dalam Meningkatkan Kompetensi Profesional Guru Pada SMA Negeri 1 Peukan Bada Kabupaten Aceh Besar. Jurnal IImiah DIDAKTIKA. VOL. XIV (2), 305-319.

Arifin, Imron. (2004). Kepemimpinan Kepala Sekolah dalam Mengelola Sekolah Berprestasi, Studi Multi Kasus Pada MIN Malang 1, MI Mambaul Ulum dan SDN NGALIK 1 Batu Malang. Malang : Aditiya Media Publishing. 